\title{
Risk factors for excessive postoperative exo-drift after unilateral lateral rectus muscle recession and medial rectus muscle resection for intermittent exotropia
}

Shin Morisawa', Ichiro Hamasaki ${ }^{1 *}$, Kiyo Shibata', Takehiro Shimizu', Reika Kono ${ }^{1}$, Manabu Miyata², Takashi Furuse ${ }^{3}$, Satoshi Hasebe ${ }^{3}$, Hiroshi Ohtsuki ${ }^{4}$, Yuki Morizane ${ }^{1}$ and Fumio Shiraga ${ }^{1}$

\begin{abstract}
Background: To detect significant factors associated with excessive postoperative exo-drift in young patients with intermittent exotropia who had undergone unilateral lateral rectus muscle recession and medial rectus muscle resection.

Methods: We retrospectively examined the records of 64 consecutive patients $<18$ years old who underwent surgery between April 2004 and December 2011. We sought risk factors for excessive postoperative exo-drift among patients' demographic and clinical characteristics using univariate and multivariable linear regression analysis.

Results: Younger patients $(P=0.007)$, and those with larger preoperative exo-deviation at distance $(P=0.033)$, a lower incidence of peripheral fusion at distance $(P=0.021)$ or a greater postoperative initial eso-deviation $(P=$ 0.001), were significantly more likely to have an excessive postoperative exo-drift (> 20 prism diopters). Univariate analysis revealed significant associations between excessive postoperative exo-drift and age at surgery $(P=0.004)$, preoperative exo-deviation at distance $(P=0.017)$ and postoperative initial eso-deviation at distance $(P<0.001)$. Multivariable linear regression analysis showed that postoperative initial eso-deviation at distance $(P=0.008)$ was significantly associated with postoperative exo-drift.

Conclusions: Postoperative exodrift in unilateral RR is predicted by the initial postoperative eso-deviation, which may offset the overcorrection. However, the exo-drift is greater in cases with a large preoperative exo-deviation and/or at a younger age, and should be followed carefully.
\end{abstract}

Keywords: Intermittent exotropia, Postoperative exo-drift, Recurrent exotropia, Recession and resection procedure, Strabismus surgery

\footnotetext{
* Correspondence: hamasaki_16@okayama-u.ac.jp

${ }^{1}$ Department of Ophthalmology, Okayama University Graduate School of

Medicine, Dentistry and Pharmaceutical Sciences, 2-5-1 Shikata-cho Kita-ku,

Okayama 700-8558, Japan

Full list of author information is available at the end of the article
}

\section{$\triangle B M C$}

(c) The Author(s). 2020 Open Access This article is licensed under a Creative Commons Attribution 4.0 International License, which permits use, sharing, adaptation, distribution and reproduction in any medium or format, as long as you give appropriate credit to the original author(s) and the source, provide a link to the Creative Commons licence, and indicate if changes were made. The images or other third party material in this article are included in the article's Creative Commons licence, unless indicated otherwise in a credit line to the material. If material is not included in the article's Creative Commons licence and your intended use is not permitted by statutory regulation or exceeds the permitted use, you will need to obtain permission directly from the copyright holder. To view a copy of this licence, visit http://creativecommons.org/licenses/by/4.0/ The Creative Commons Public Domain Dedication waiver (http://creativecommons.org/publicdomain/zero/1.0/) applies to the data made available in this article, unless otherwise stated in a credit line to the data. 


\section{Background}

In the surgical treatment of intermittent exotropia, most clinicians aim to achieve overcorrection at the initial postoperative examination $[1,2]$. Exotropia may recur gradually over months or years after surgery, a phenomenon known as postoperative exo-drift [3]. Ideally subsequent postoperative exo-drift should cancel out any overcorrection, but unexpectedly large postoperative exo-drift can result in recurrent exotropia. Excessive postoperative exo-drift diminishes the long-term surgical success rate, and makes it difficult to compare the findings of studies in which outcomes were recorded at different follow-up period. A better understanding of excessive exo-drift, the risk factors and means of preventing it are needed. In many studies of intermittent exotropia, patients had undergone a variety of procedures, including bilateral lateral rectus muscle recession (BLR), unilateral recession and resection (RR) or unilateral lateral rectus muscle recession (ULR), making it difficult to interpret the findings due to the potential influence of surgical technique on exo-drift [4-7]. We examined the factors associated with postoperative exo-drift in young patients with intermittent exotropia who had undergone only unilateral RR to establish risk factors for recurrent exotropia.

\section{Methods}

The records of a series of 64 consecutive patients aged < 18 years with intermittent exotropia who underwent unilateral RR surgery between April 2004 and December 2011 at Okayama University Hospital were examined retrospectively. Subjects were 31 males (48\%) and $33 \mathrm{fe}$ males (52\%). Operated eyes were 29 right (45\%) and 35 left (55\%). We excluded the following example: preoperative vertical deviation of $>5$ prism diopters (PD), dissociated vertical deviation, previous strabismus surgery, surgery with vertical transposition, other disease causing ocular deviation (for example, thyroid ophthalmopathy, myasthenia gravis, internuclear ophthalmoplegia, high grade myopia, orbital dysplasia, paretic strabismus, sensory strabismus or other neurologic disorders).

We recorded age at surgery, preoperative angle of deviation at distance $(5 \mathrm{~m}$ ) (a negative value indicating exodeviation, and a positive value eso-deviation), preoperative near-distance disparity in angle of deviation (by subtracting distance angle of deviation from near $(33 \mathrm{~cm})$ angle of deviation; positive value indicating convergence insufficiency), the refractive error in the operative eye, the difference between the refractive error of both eyes, the difference between the visual acuity of both eyes using the logarithm of minimum angle of resolution (logMAR), stereoacuity threshold using the TNO test (Ootech, AG Veeneldaal, Netherlands) transformed to log seconds of $\operatorname{arc}(\operatorname{arcsec})$, the presence or absence of peripheral fusion at distance and near (assigned a value of 1 or 0 , respectively and assessed using the Bagolini striated glass test), the postoperative initial angle of deviation at distance, the postoperative initial near-distance disparity and last postoperative angle of deviation. The Shapiro-Wilk Test was used to assess data for normality. The stereoacuity threshold was 1980 arcsec (range 15 arcsec to 33 arcmin) measured using the TNO test. Absence of stereopsis using the TNO was assigned a value of the next level to 66 arcmin. The assignment of the next log level is commonly used in analysis of stereoacuity data and allows for calculations of changes in stereoacuity.

The extent of preoperative angle of exodeviation at distance fixation was recorded in each subject by means of the PAT, using the Fresnel Press-On Prism (Health Care Specialties Division/3 M; St. Paul, MN, USA), which was attached to glasses at two equal parts of the PD to neutralize the angle of deviation. The PD was adjusted according to responses to deviation as determined by the prism and cover test (PCT), and the test was repeated at 20-min intervals until no additional prisms were required to neutralize the distance deviation. The amount of surgery was determined by measurements at distance fixation [8]. Preoperatively, the hole-in-the-card test was performed to determine the dominant eye. The eye the patient used to view the target through the hole was defined as the dominant eye. Surgery was performed on the nondominant eye. The amount of surgery was based on the smallest angle of deviation at distance or near fixation. In all cases, the same amount ( $1 \mathrm{~mm}$ per $5 \mathrm{PD})$ of lateral rectus muscle recession and medial rectus muscle resection was carried out, referring to the strabismus surgical amount table of Okayama University Hospital. The alternative prism cover test was used to measure angle of deviation approximately 1 week and 1 year after surgery due to the small residual angle of deviation [9]. The difference between the angle of deviation recorded at the initial examination and that recorded at the last examination was defined as postoperative exo-drift (Fig. 1).

Patients were divided into two groups according to the extent of postoperative exo-drift: those with excessive postoperative exo-drift $>20$ PD were allocated to group A; those with postoperative exo-drift $\leq 20$ PD to group B. Data are presented as mean \pm SD unless otherwise stated. The Mann-Whitney $U$ test was used to test for significant differences between the groups. Correlation analyses were used to assess the strength of the association between each pre-drift parameter and postoperative exo-drift and expressed as the Spearman rank-correlation. These findings were used to inform subsequent multivariable linear regression analysis using a direct entry method. We used IBM SPSS Statistics for Windows, Version 22.0 (IBM. Corp., Armonk, NY, USA) for all statistical analyses.

\section{Results}

The mean age at surgery was $9.4( \pm 3.5)$ years (range: $5-$ 17 years); patients' pre-drift parameters are shown in 


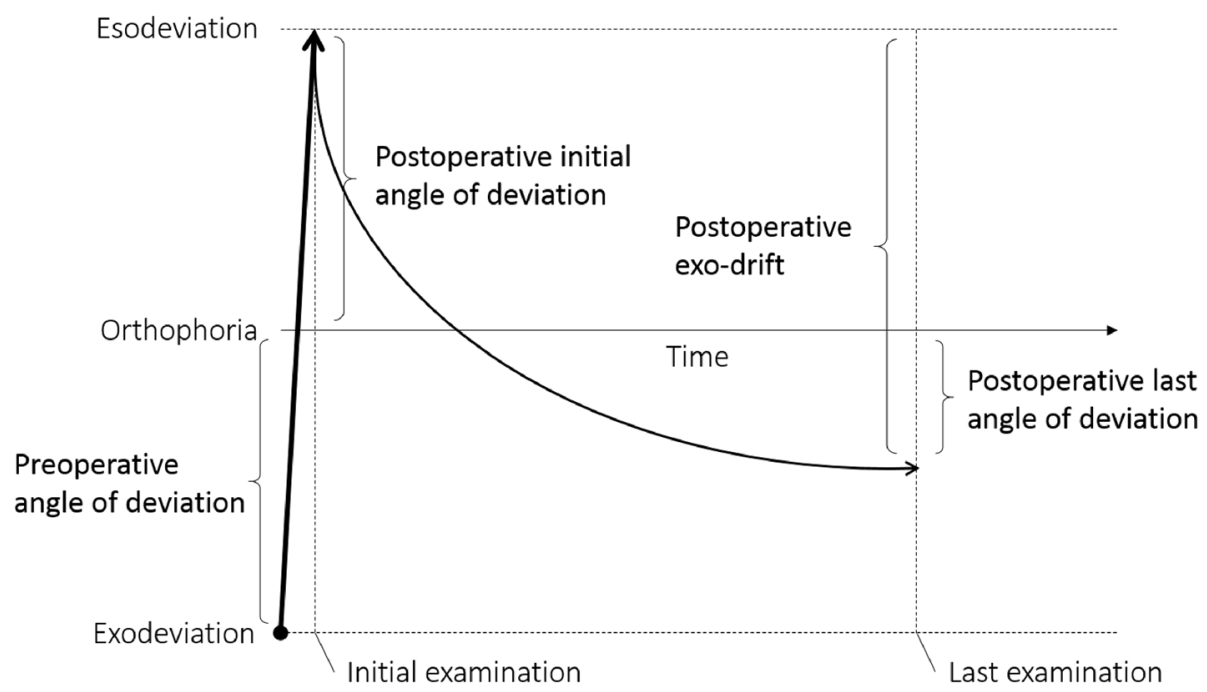

Fig. 1 Definitions of outcome measures. Horizontal axis, time; vertical axis, angle of deviation; bold arrow, surgery

Table 1. The mean time elapsed to the first postoperative examination was $6.2( \pm 1.7)$ days (range: $1-13$ days) and to the last examination was $650( \pm 195)$ days (range: $295-1153$ days). Postoperative elapsed time to the last examination did not significantly relate to postoperative exo-drift and correlation coefficient was $-0.124(P=0.329)$. The mean last postoperative angle of deviation at distance was -5.0 $( \pm 4.9)^{\circ}$ (range: $\left.-16.7-9.1^{\circ}\right)$ : a negative value indicating exotropia. Mean post-operative exo-drift was $-12.2 \pm 4.6^{\circ}$ (range: $-23.1--3.4^{\circ}$ ). None of the parameters were normally distributed, therefore relationships between the parameters were assessed using Spearman rank-correlation.

Characteristics of patients with postoperative exo-drift $>20 \mathrm{PD}$ and $\leq 20 \mathrm{PD}$ are shown in Table 2. Those with excessive postoperative exo-drift (Group A) were significantly younger at surgery, had greater preoperative exodeviation, a lower incidence of peripheral fusion, greater overcorrection at the initial postoperative examination and larger last postoperative exo-deviation than those with less postoperative exo-drift (Group B).

On correlation analysis, relationships between clinical characteristics and postoperative exo-drift are shown in Table 3. Greater postoperative exo-drift was associated with younger age at surgery, larger preoperative exodeviation at distance and greater initial postoperative eso-deviation at distance.

Multiple linear regression analysis was also performed. Postoperative exo-drift was defined as the dependent variable, and other pre-drift parameters were defined as the independent variables. The only significantly influential factor was initial postoperative angle of deviation at distance $(P=0.008$, Table 4$)$.

\section{Discussion}

Age at surgery correlated with postoperative exo-drift in our cohort, with younger patients more likely to develop

Table 1 Subjects' summary in pre-drift parameters

\begin{tabular}{|c|c|}
\hline Amount of recession / resection (SD) (range) & $6.4(1.3) \mathrm{mm}(4.0-9.0)$ \\
\hline Preoperative angle of deviation at distance (SD) (range) & $-17.5(3.7)^{\circ}(-27.6--10.3)$ \\
\hline Preoperative near-distance disparity (SD) (range) & $2.2(3.3)^{\circ}(-5.7-11.0)$ \\
\hline Refractive error in the operative eye (SD) (range) & -1.1 (2.1) diopters $(-10.1-5.9)$ \\
\hline Difference between refractive error of both eyes (SD) (range) & 0.5 (0.8) diopters $(0.0-4.4)$ \\
\hline Difference between visual acuity of both eyes (SD) (range) & $0.0(0.1)(0.0-0.2)$ \\
\hline Stereoacuity threshold transformed to log (SD) (range) & $2.0(0.6) \log \operatorname{arcsec}(1.2-3.6)$ \\
\hline Peripheral fusion at distance fixation (proportion) & $22(34 \%)$ \\
\hline Peripheral fusion at near fixation (proportion) & $48(75 \%)$ \\
\hline Initial postoperative angle of deviation at distance (SD) (range) & $7.3(5.2)^{\circ}(-2.9-21.8)$ \\
\hline Initial postoperative near-distance disparity (SD) & $1.8(4.3)^{\circ}(-11.9-10.8)$ \\
\hline
\end{tabular}


Table 2 Characteristics of patients with postoperative exo-drift $>20$ PD and $\leq 20$ PD.

\begin{tabular}{|c|c|c|c|}
\hline Parameter & Group A $(n=36)$ & Group B $(n=28)$ & $P$ value \\
\hline Age at surgery & $8.4 \pm 2.8$ & $10.8 \pm 3.8$ & $0.007 *$ \\
\hline Preoperative angle of deviation at distance & $-18.3 \pm 3.8^{\circ}$ & $-16.4 \pm 3.2^{\circ}$ & $0.033 *$ \\
\hline Preoperative near-distance disparity in deviation & $1.5 \pm 3.4^{\circ}$ & $3.1 \pm 3.1^{\circ}$ & 0.088 \\
\hline Refractive error in the operative eye & $-0.8 \pm 1.5$ & $-1.3 \pm 2.8$ & 0.091 \\
\hline Difference between refractive error of both eyes & $0.4 \pm 0.5$ & $0.7 \pm 1.1$ & 0.113 \\
\hline Difference between visual acuity of both eyes & $0.027 \pm 0.041$ & $0.045 \pm 0.060$ & 0.257 \\
\hline Stereoacuity values transformed to log arcsec & $2.1 \pm 0.6$ & $2.0 \pm 0.6$ & 0.799 \\
\hline Peripheral fusion at distance & $22 \pm 42 \%$ & $50 \pm 51 \%$ & $0.021 *$ \\
\hline Peripheral fusion at near & $78 \pm 42 \%$ & $71 \pm 46 \%$ & 0.564 \\
\hline Initial postoperative angle of deviation at distance & $9.3 \pm 5.1^{\circ}$ & $4.7 \pm 4.0^{\circ}$ & $0.001 *$ \\
\hline Initial postoperative near-distance disparity in deviation & $2.1 \pm 4.5^{\circ}$ & $1.4 \pm 4.1^{\circ}$ & 0.357 \\
\hline Last postoperative angle of deviation at distance & $-6.3 \pm 5.5^{\circ}$ & $-3.4 \pm 3.5^{\circ}$ & $0.017 *$ \\
\hline Postoperative elapsed time to the last examination & $660 \pm 199$ days & $636 \pm 193$ days & 0.756 \\
\hline
\end{tabular}

All data are presented as mean \pm standard deviation

* represents statistical significance $(P<0.05)$

greater exo-drift. Yam and colleagues reported that a non-significant trend suggestive that age at surgery influenced exo-drift in patients undergoing BLR because their report limited the age to $96.5 \pm 43.8$ months [10]. However, range of age at surgery was more variable in this study. We consider age at surgery to be a key preoperative influencer of postoperative exo-drift, likely because of degeneration of orbital connective tissue that effects ocular alignment with aging $[11,12]$.

Age at surgery has been reported not to influence final outcome after RR surgery in the short-, medium- or long-term in some previous reports $[13,14]$. In our cohort, age at surgery correlated with postoperative initial angle of deviation, with the most extensive eso-deviation seen in younger patients: the younger the age at surgery, the larger the exo-drift and eso-deviation in the initial postoperative examination. Thereafter, compensating exo-drift may mean that the difference in postoperative deviation at initial examination between younger and older ages may become weak or absent in the longer term.

Both univariate and multivariable analysis identified initial postoperative angle of deviation at distance as being significantly associated with postoperative exo-drift. In addition, the initial overcorrection was significantly greater in those with excessive postoperative exo-drift > 20 PD than those with exo-drift $\leq 20 \mathrm{PD}$, a relationship also reported by Yam and colleagues [10]. The greater the overcorrection after surgery, the larger the exo-drift. Exo-drift may therefore balance out overcorrection, a hypothesis confirmed by reports that initial postoperative angle of deviation is not associated with angle of deviation 1 year or more after surgery [10, 15-17]. This also agrees with Park and colleagues' report that the rate

Table 3 Relationships between clinical characteristics and postoperative exo-drift

\begin{tabular}{lll}
\hline Pre-drift parameter & Correlation coefficient & $P$ value \\
\hline Age at surgery & $\mathbf{0 . 3 5 7}$ & $\mathbf{0 . 0 0 4}$ \\
Preoperative angle of deviation at distance & $\mathbf{0 . 2 9 6}$ & $\mathbf{0 . 0 1 7} *$ \\
Preoperative near-distance disparity in deviation & 0.240 & 0.056 \\
Refractive error in the operative eye & -0.191 & 0.130 \\
Difference between refractive error of both eyes & 0.237 & 0.059 \\
Difference between visual acuity of both eyes & 0.223 & 0.076 \\
Stereoacuity transformed to log arcsec & -0.005 & 0.971 \\
Peripheral fusion at distance & -0.066 & 0.604 \\
Peripheral fusion at near & 0.064 & 0.613 \\
Initial postoperative angle of deviation at distance & $\mathbf{- 0 . 5 6 0}$ & $<\mathbf{0 . 0 0 1} *$ \\
Initial postoperative near-distance disparity in deviation & -0.139 & 0.275 \\
\hline
\end{tabular}

*represents statistical significance $(P<0.05)$ 
Table 4 Multivariable linear regression analysis using a direct entry method

\begin{tabular}{|c|c|c|c|}
\hline Coefficient of determination in this model & 0.426 & & \\
\hline$P$-value in analysis of variance in this model & 0.001 & & \\
\hline Pre-drift parameter & Unstandardized coefficients & Standardized coefficients & $P$ value \\
\hline Age at surgery & -0.378 & 0.282 & 0.055 \\
\hline Preoperative angle of deviation at distance & 0.238 & 0.188 & 0.116 \\
\hline Preoperative near-distance disparity in deviation & 0.098 & 0.070 & 0.614 \\
\hline Refractive error in the operative eye & -0.171 & -0.079 & 0.543 \\
\hline Difference between refractive error of both eyes & 0.162 & 0.029 & 0.830 \\
\hline Difference between visual acuity of both eyes & 18.3 & 0.200 & 0.177 \\
\hline Stereoacuity values transformed to log arcsec & 0.197 & 0.024 & 0.860 \\
\hline Peripheral fusion at distance & 0.700 & 0.076 & 0.498 \\
\hline Peripheral fusion at near & 0.819 & 0.062 & 0.634 \\
\hline Initial postoperative angle of deviation at distance & -0.311 & -0.347 & $0.008 *$ \\
\hline Initial postoperative near-distance disparity in deviation & -0.268 & -0.248 & 0.070 \\
\hline Constant & -10.9 & & 0.040 \\
\hline
\end{tabular}

* represents statistical significance $(P<0.05)$

of exo-drift is greater in those with more extensive overcorrection immediately after surgery [18], and a report that surgical outcome is not significantly different between traditional BLR and a surgical technique modified by reducing the amount of resection by $1-2 \mathrm{~mm}[19]$.

Preoperative angle of exo-deviation is reportedly associated with postoperative exo-drift in patients who underwent BLR $[10,17]$. We also detected this relationship in our patients: more extensive preoperative exodeviation appeared to predict more extensive postoperative exo-drift. In addition, the preoperative angle of exodeviation was greater in those with excessive postoperative exo-drift (Group A) than those with postoperative exo-drift $\leq 20$ PD (Group B). Surgeons should consider the potential for postoperative exo-drift to result in excessive exo-deviation in each case of RR or BLR.

We found that those with postoperative exo-drift $>20$ PD had greater last postoperative exo-deviation despite an initially larger initial postoperative eso-deviation than those with postoperative exo-drift $\leq 20 \mathrm{PD}$. An unexpectedly large postoperative exo-drift is an important risk factor for recurrent exotropia. In consideration of comparing between two groups, a lower incidence of peripheral fusion at distance might have been expected to influence the extent of postoperative exo-drift, but we found no significant relationship in either our univariate or multivariable analyses.

It is difficult to compare our findings with those of other investigators due to the possibility that surgical approach influenced the extent of exo-drift [4-7], although there have been reports that surgical technique is not a significant risk factor for exo-drift $[13,18,20]$. The influence of surgical technique on exo-drift remains a matter of considerable debate. Intermittent exotropia associated with $\mathrm{A}$ and $\mathrm{V}$ patterns is also reportedly associated with less postoperative exo-drift [21], but these patients were excluded from our analysis.

In addition, last postoperative examinations were approximate 1 year or later and variety in this retrospective study. It has little effect on our results because postoperative exo-drift is considered to be stable after postoperative 1 year [22]. Because of significant difference in the amount of postoperative exo-drift by age, this study has the advantage of limiting the age to less than 18 years. Cases were limited to unilateral RR. Accordingly, the number of cases has been limited. This study does not include information on the amount of time participants had a manifest deviation. Therefore, the level of control of their deviation cannot be evaluated. In the Bagolini striated glass test in this study, the sensory fusion and motor fusion could not be separated because the prism was not used to correct the eye position.

\section{Conclusions}

We found that in our cohort of young patients undergoing unilateral RR for intermittent exotropia, younger age at surgery, greater preoperative exo-deviation and greater postoperative initial eso-deviation were significantly associated with greater postoperative exo-drift. Postoperative exo-drift in unilateral RR is predicted by the initial postoperative eso-deviation at a distance, which may offset the overcorrection. However, the exodrift is greater in cases with a large preoperative exodeviation at a distance and/or at a younger age, and should be followed carefully. Our findings will help for predicting and evaluating postoperative exo-drift. 


\section{Abbreviations}

BLR: Bilateral lateral rectus muscle recession; RR: Recession-resection; ULR: Unilateral lateral rectus muscle recession; PD: Prism diopters; PAT: Prism adaptation test; SD: Standard deviations; arcsec: Arc second; arcmin: Arc minute

\section{Acknowledgements}

Not applicable.

\section{Authors' contributions}

$\mathrm{SM}$ and $\mathrm{IH}$ contributed in conception and design and writing the manuscript. KS and MM contributed in acquisition of data, SM and TS contributed in analysis and interpretation of data, RK, TF, SH, HO, YM and FS contributed in critical revision for intellectual content, FS contributed in supervision. The authors read and approved the final manuscript.

\section{Funding}

This work was supported by JSPS KAKENHI Grant Numbers JP23791987, JP26861450. This funding source had no role in the design of this study and will not have any role during its execution, analyses, interpretation of the data, or decision to submit results.

\section{Availability of data and materials}

The datasets used and/or analysed during the current study are available from the corresponding author on reasonable request.

\section{Ethics approval and consent to participate}

The Ethics Committee of Okayama University Hospital approved this retrospective study and waived informed consent to participate who received medical treatment at Okayama University Hospital. (No. K1507-021).

\section{Consent for publication}

Not applicable.

\section{Competing interests}

The authors declare that they have no competing interests.

\section{Author details}

'Department of Ophthalmology, Okayama University Graduate School of Medicine, Dentistry and Pharmaceutical Sciences, 2-5-1 Shikata-cho Kita-ku, Okayama 700-8558, Japan. ${ }^{2}$ Department of Ophthalmology and Visual Sciences, Kyoto University Graduate School of Medicine, 54 Kawahara-cho, Shogoin, Sakyo-ku Kyoto 606-8507, Japan. ${ }^{3}$ Department of Ophthalmology, Kawasaki Medical School General Medical Center, 2-6-1 Nakasange Kita-ku, Okayama 700-8505, Japan. ${ }^{4}$ Division of Ophthalmology, Okayama Saiseikai General Hospital, 2-25 Kokutai-cho Kita-ku, Okayama 700-8511, Japan.

Received: 19 March 2019 Accepted: 26 May 2020

Published online: 05 June 2020

\section{References}

1. Raab EL, Parks MM. Recession of the lateral recti. Early and late postoperative alignments. Arch Ophthalmol. 1969;82:203-8.

2. Scott WE, Keech R, Mash AJ. The postoperative results and stability of exodeviations. Arch Ophthalmol. 1981;99:1814-8.

3. Ekdawi NS, Nusz KJ, DiehI NN, Mohney BG. Postoperative outcomes in children with intermittent exotropia from a population-based cohort. AAPOS. 2009;13:4-7.

4. Kim HJ, Choi DG. Consecutive esotropia after surgery for intermittent exotropia: the clinical course and factors associated with the onset. $\mathrm{Br}$ J Ophthalmol. 2014;98:871-5.

5. Heo H, Sung MS, Park SW. Surgical outcomes of symmetric and asymmetric surgery for intermittent exotropia with postoperative large early overcorrection. Jpn J Ophthalmol. 2013:57:475-80.

6. Choi J, Chang JW, Kim SJ, Yu YS. The long-term survival analysis of bilateral lateral rectus recession versus unilateral recession-resection for intermitten exotropia. Am J Ophthalmol. 2012;153:343-51.

7. Pukrushpan $\mathrm{P}$, Isenberg SJ. Drift of ocular alignment following strabismus surgery. Part 1: using fixed scleral sutures. Br J Ophthalmol. 2009;93:439-42.
8. Ohtsuki H, Hasebe S, Kono R, Yamane T, Fujiwara H, Shiraga F. Prism adaptation response is useful for predicting surgical outcome in selected types of intermittent exotropia. Am J Ophthalmol. 2001;131:117-22.

9. Hatt SR, Leske DA, Liebermann L, Mohney BG, Holmes JM. Variability of angle of deviation measurements in children with intermittent exotropia. J AAPOS. 2012;16:120-4

10. Yam JC, Chong GS, Wu PK, Wong US, Chan CW, Ko ST. Predictive factors affecting the short term and long term exodrift in patients with intermittent exotropia after bilateral rectus muscle recession and its effect on surgical outcome. Biomed Res Int. 2014. https://doi.org/10.1155/2014/482093.

11. Demer JL. More respect for connective tissues. J AAPOS. 2008;12:5-6.

12. Stager D Jr, McLoon LK, Felius J. Postulating a role for connective tissue elements in inferior oblique muscle overaction (an American ophthalmological society thesis). Trans Am Ophthalmol Soc. 2013;111:11932

13. Gezer A, Sezen F, Nasri N, Gözüm N. Factors influencing the outcome of strabismus surgery in patients with exotropia. J AAPOS. 2004;8:56-60.

14. Pineles SL, Ela-Dalman N, Zvansky AG, Yu F, Rosenbaum AL. Long-term results of the surgical management of intermittent exotropia. J AAPOS. 2010;14:298-304.

15. Pineles SL, Deitz LW, Velez FG. Postoperative outcomes of patients initially overcorrected for intermittent exotropia. J AAPOS. 2011;15:527-31.

16. Park JH, Kim SH. Clinical features and the risk factors of infantile exotropia recurrence. Am J Ophthalmol. 2010;150:464-7.

17. Leow PL, Ko ST, Wu PK, Chan CW. Exotropic drift and ocular alignment after surgical correction for intermittent exotropia. J Pediatr Ophthalmol Strabismus. 2010;47:12-6.

18. Park KH, Kim SY. Clinical characteristics of patients that experience different rates of exodrift after strabismus surgery for intermittent exotropia and the effect of the rate of exodrift on final ocular alignment. J AAPOS. 2013;17:548.

19. Nam KT, Kim SH. Traditional and reduced recession surgical amount for bilateral lateral rectus recession for infantile exotropia. Br J Ophthalmol. 2014;98:1420-3.

20. Lee JY, Ko SJ, Baek SU. Survival analysis following early surgical success in intermittent exotropia surgery. Int J Ophthalmol. 2014;7:528-33.

21. Pineles SL, Rosenbaum AL, Demer JL. Decreased postoperative drift in intermittent exotropia associated with a and V patterns. J AAPOS. 2009;13: 127-31

22. Hamasaki I, Shibata K, Shimizu T, Morisawa S, Toshima S, Miyata M, et al. Differences in the stability and amount of postoperative exodrift with age after unilateral lateral rectus muscle recession and medial rectus muscle resection of intermittent exotropia. Acta Med Okayama. 2018;72:487-92.

\section{Publisher's Note}

Springer Nature remains neutral with regard to jurisdictional claims in published maps and institutional affiliations.

Ready to submit your research? Choose BMC and benefit from:

- fast, convenient online submission

- thorough peer review by experienced researchers in your field

- rapid publication on acceptance

- support for research data, including large and complex data types

- gold Open Access which fosters wider collaboration and increased citations

- maximum visibility for your research: over $100 \mathrm{M}$ website views per year

At $\mathrm{BMC}$, research is always in progress.

Learn more biomedcentral.com/submissions 